\title{
Cúvítưtura
}

Vol. XIV, N 2 (2020) pp. 36-55

Recibido: 14 de octubre, 2019

Aceptado: 21 de julio, 2020

\section{SENTIDOS DA MEDIUNIDADE NOS CANDOMBLÉS KETU E EFON*}

\author{
Meanings of mediumship in the Ketu and Efon candomblé
}

\author{
Fabio Scorsolini-Comin ${ }^{* *}$ \\ fabio.scorsolini@usp.br
}

\author{
Helena Vilela de Godoy ${ }^{* * *}$ \\ helenagodoy@usp.br
}

\author{
Ronan da Silva Parreira Gaia ${ }^{\text {*******}}$ \\ ronangaia@yahoo.com.br
}

Universidad de São Paulo, USP

\begin{abstract}
Resumo
Com as perspectivas socioantropológicas, a mediunidade passou a ser considerada um fenômeno cultural e religioso legítimo. O objetivo deste estudo bioecológico foi compreender como a mediunidade é concebida por médiuns do candomblé que realizaram a feitura (iniciação) de sete anos. Participaram 17 médiuns das nações Ketu e Efon da cidade de Uberaba-MG (Brasil), que responderam a um roteiro de entrevista contendo questões acerca da experiência da mediunidade, da iniciação no candomblé e da história de vida do participante. A mediunidade foi verbalizada de dois modos distintos: como um dom que não pode ser recusado pelo médium; como uma faculdade que pode ser controlada/recusada pelo médium. Entre os aspectos relacionados às sensações corpóreas da possessão, destacaram movimentos opostos que vão desde a paralisia até a agitação do corpo, explicados a partir da energia de cada orixá. Discute-se que esses médiuns encontram-se engajados em compartilhar experiências que evoquem fundamentalmente os aspectos positivos relacionados à mediunidade, incorporando, inclusive, uma gramática científica que visa a explicar o fenômeno. Em um cenário de intolerância e racismo, este parece ser um movimento que valoriza a mediunidade e a coloca em uma posição de destaque dentro das expressões das religiões de matriz africana.
\end{abstract}

Palavras-chave: mediunidade, candomblé, cultura afro-brasileira, desenvolvimento humano, modelo bioecológico.

\footnotetext{
* Este artículo se enmarca dentro del proyecto de investigación titulado "Mediunidade e processos desenvolvimentais: histórias de vida de médiuns e intervenções etnopsicológicas em saúde mental", al alero del Conselho Nacional de Desenvolvimento Científico e Tecnológico (CNPq), cuyo coordinador es Fabio Scorsolini-Comin.

*** Doctor en Psicología, Universidad de São Paulo. Profesor, Escuela de Enfermería de Ribeirão Preto, Universidad de São Paulo. ORCID: http://orcid.org/0000-0001-6281-3371

**** Estudiante de Enfermería de la Escuela de Enfermería de Ribeirão Preto, Universidad de São Paulo. ORCID: https://orcid.org/0000-0001-6256-7166

${ }_{* * * * *}$ Estudiante de Maestría en el Programa de Posgrado en Enfermería Psiquiátrica, Escuela de Enfermería de Ribeirão Preto, Universidad de São Paulo. ORCID: https://orcid.org/0000-0003-2342-0019
} 


\begin{abstract}
With socio-anthropological perspectives, mediumship started to be considered a legitimate cultural and religious phenomenon. The aim of this bioecological study was to understand how mediumship is conceived by Candomblé mediums who performed seven years. Seventeen mediums from the nations Ketu and Efon from the city of Uberaba-MG (Brazil) took part, and answered an interview script containing questions about the mediumship experience, initiation in candomblé and the participant's life story. Mediumship was verbalized in two distinct ways: as a gift that cannot be refused by the medium; and as a faculty that can be controlled/refused by the medium. Among the aspects related to the bodily sensations of possession, they highlighted opposite movements ranging from paralysis to agitation of the body, explained in terms of the energy of each orixá. It can be argued that these mediums are engaged in sharing experiences that fundamentally evoke the positive aspects related to mediumship, including, even, a scientific grammar that aims to explain the phenomenon. In a scenario of intolerance and racism, this seems to be a movement that values mediumship and places it in a prominent position within the expressions of religions of African origin.
\end{abstract}

Keywords: mediumship, candomblé, Afro-Brazilian culture, human development, bioecological model.

\title{
Introdução
}

O estudo científico da mediunidade já foi alvo de diversos preconceitos e tabus dentro e fora dos meios acadêmicos. No entanto, não pode ser ignorado pelas ciências humanas, sociais e da saúde enquanto fenômeno presente nas mais diversas sociedades e em diferentes tempos históricos, atrelados a diferentes religiosidades (Zangari, 2003). Em tempos como os que temos vivenciado no contexto brasileiro, de explícitas intolerâncias e discursos de ódio às religiões afro-brasileiras como a umbanda e o candomblé (Gaia, Vitória e Roque, 2020; Silva, 2015;), embora ainda exista no imaginário internacional e nacional a perspectiva de liberdade religiosa brasileira e da convivência pacífica entre diferentes religiosidades neste território (Carvalho e Fernández, 2017; Montero, 2013; Oliveira, 2016), torna-se premente trazer a questão da mediunidade à tona, a fim de que esse fenômeno possa ser compreendido dentro de sua manifestação ritual, social e religiosa, fortalecendo as tradições dos povos de santo com vistas à sua preservação e continuidade em nossa sociedade.

Todavia, é preciso tomar certas precauções, a fim de não reproduzir estigmas que marginalizaram as culturas religiosas atreladas à mediunidade, possibilitando, assim, a realização de um trabalho condizente com a complexidade requerida pelo assunto (Scorsolini-Comin, 2019). No presente estudo, o foco será no fenômeno da mediunidade a partir da experiência religiosa vivenciada no candomblé. Assim, torna-se oportuno refletir sobre como este termo tem sido empregado neste contexto e por que o mesmo será empregado neste estudo. 


\section{A mediunidade e os terreiros de candomblé}

A mediunidade não é uma categoria nativa do candomblé, o que nos obriga a legitimar o seu uso na presente investigação. Embora outras noções possam ser recuperadas, como a incorporação, o transe mediúnico e o transe de possessão, apenas para citar alguns exemplos, há que se considerar que essa diversidade se deve, entre outros, à organização de cada terreiro, suas ancestralidades e ao modo como cada comunidade produz sentidos sobre essas experiências. Assim, esses termos, em dadas comunidades, podem ser tomados ora como sinônimos, ora como complementares, ora como distanciados epistemologicamente.

Em que pesem as possíveis diferenças, a opção pelo termo mediunidade retoma o próprio contexto empírico do presente estudo, de modo que a mediunidade é a noção mais evocada não apenas nos terreiros investigados, mas de modo mais amplo no município de Uberaba, Estado de Minas Gerais. Esse município apresenta uma forte ligação com o espiritismo kardecista, o que se torna emblemático também em função da presença do médium Chico Xavier e do seu renome internacional, sobretudo a partir da década de 1970 (Paraná, Rocha, Freire, Lotufo Neto e Moreira-Almeida, 2019), o que é de particular interesse no presente estudo, haja vista que se trata de um estudo realizado nesta cidade, terra na qual este médium viveu por muitos anos. Como afirmado anteriormente, esta cidade possui forte ancoragem no espiritismo kardecista, podendo derivar dessa ancestralidade a recuperação do termo e o seu emprego em diversos contextos religiosos, tanto no espiritismo como na umbanda e no candomblé, como apontado em estudo anterior realizado no mesmo contexto (Scorsolini-Comin, Ribeiro e Gaia, 2020). Movimento semelhante foi observado em estudos realizados no eixo sudeste (Godoy e Bairrão, 2014; Scorsolini-Comin e Campos, 2017).

Assim como destacado por Prandi (1990) e também recuperado por Gaia et al. (2020), o candomblé do sudeste tem uma ampla relação com a umbanda, constituindo-se aí um diálogo inequívoco. No entanto, há que se destacar que o candomblé existe independentemente da umbanda, haja vista que não depende estruturalmente de outras matrizes. Esses apontamentos também se tornam lícitos a partir do que tem sido compreendido como porosidade religiosa (Augras, 2012), em substituição ao conceito de sincretismo. A porosidade, desse modo, permitiria o diálogo e, ao mesmo tempo, a manutenção das identidades e ancestralidades de cada religião. A partir desse ponto de ancoragem, o termo mediunidade parece recobrir de modo mais apropriado a diversidade de fenômenos narrados pelos adeptos do estudo em tela, como poderemos compreender mais adiante.

Originário da França, o espiritismo kardecista expandiu-se por todo o mundo (Ludueña, 2013), encontrando sólido campo para o seu desenvolvimento no Brasil. O termo "médium", fortemente presente nessa tradição, é um neologismo criado por Allan Kardec, que explicita o seu significado da seguinte forma: "Médium, do latim - medium, meio, intermediário - pessoa que pode servir de intermediária entre os Espíritos e os homens" (Kardec, 2003, p. 577). Kardec definiu mediunidade como a "faculdade dos médiuns".

A mediunidade possui outras definições, que geralmente se encontram ligadas a hipóteses pré-determinadas acerca do fenômeno mediúnico (Scorsolini-Comin, 2019). A mediunidade, apesar de seus múltiplos conceitos e modalidades, variando conforme o contexto social e grupal em que está inserida, depende da capacidade que o indivíduo tem de se comunicar com as entidades que habitam um plano distinto do terreno. Segundo Zangari 
(2003), essa capacidade tende a ser produzida em um estado de consciência alterada, um estado de transe, ou qualquer outra definição de estado mental que implique certa inconsciência por parte do médium.

Partimos do princípio de que é preciso considerar o papel do médium como unificado, e não como a simples soma dos "espíritos" ou facetas de sua identidade manifestadas no estado de transe (Zangari, 2003). Entende-se também que o médium é aquele que tem a capacidade de assumir múltiplas posições ou cargos, enquanto os espíritos são manifestações de papéis sociais, mas que não permitem aos médiuns exercer qualquer controle sobre eles. Os médiuns, por sua vez, são considerados, ao mesmo tempo, intérpretes e coautores de suas entidades (Augras, 1983), em um duplo processo de construção identitária - tanto o médium dá voz e corpo à entidade como esta lhe confere determinadas características. Essa consideração de duplo pertencimento também é destacada no estudo de Godoy e Bairrão (2014) no contexto da umbanda. Tais apontamentos também fazem coro à perspectiva cultural de identidade trazida na pós-modernidade por Hall (2006), em que se opera o chamado "jogo das identidades", pondo em relevo a noção de uma identidade construída perenemente a partir de embates e de movimentos de permanências e descontinuidades.

\section{Ser médium no candomblé: iniciações, feituras e costuras identitárias}

O terreiro de candomblé é um espaço fortemente hierarquizado, liderado por um Babalorixá ou Iyalorixá (popularmente chamados de pai e mãe de santo) que são responsáveis pelos filhos de santo (iniciados ou não no candomblé), pelos processos iniciáticos, pelas obrigações ou festividades e pelas entidades (exus e caboclos, por exemplo), cultuados quando o responsável pelo terreiro possui relação com a Umbanda, fator que pode ser encontrado em muitos terreiros do sudeste. Os grupos dos filhos de santos são diferenciados a partir do critério de experiência ou não com possessão. Eles são divididos entre os rodantes, aqueles que são tomados por suas entidades e são suscetíveis ao transe de possessão, e as Èkèjí (se mulheres) ou Ogan (se homens), os quais assumem funções específicas na casa e não têm a manifestação mediúnica de sua divindade.

Os filhos de santo possuem também o critério etário, definido pela idade de iniciação, que é operado mais fortemente no grupo dos rodantes. Dessa maneira, distinguem-se ainda em Abiã (adeptos ainda não iniciados, porém já incorporados à casa), Iyawo (iniciados que ainda não completaram a obrigação de sete anos de iniciação), e Egbon (adeptos que possuem a obrigação de sete anos, ingressando no grupo dos "mais velhos" - o próprio termo, Egbon, significa "irmão mais velho"). Dentro do terreiro (ou Ile -Casa, ou Ilesin- Casa de culto) esses Egbon serão chamados por todos os mais novos de Egbon-mi, ou seja, "meu irmão mais velho", em referência à sua idade de iniciação e de já possuir o Odun Meje (obrigação de sete anos) e, consequentemente, ter vivência dentro do terreiro, sendo aptos a responsabilizar-se pela educação de terreiro daqueles mais novos. As Èkèjí e os Ogan já “nascem velhos". Desta forma, a diferença entre Ogan, Èkèjí e os rodantes diz respeito mais ao grau do que à natureza, ou seja, uns já "nascem" velhos/grandes, e os outros têm que "crescer" para isso.

O processo de iniciação, referido por Goldman (1985) como "feitura do santo", corresponde à "feitura da cabeça", de constituição de uma nova pessoa. Para Rabelo (2014, p. 111), "a feitura no candomblé é 'criar' uma relação à qual a mãe de santo é tão essencial quanto os outros conciliadores que fazem parte do terreiro. Contudo, a iniciação ensina que 
aprender no Candomblé significa saber sujeitar-se". A autoridade e a sabedoria são controladas pelas próprias entidades ou por aqueles que têm mais tempo de feitura: saber menos no candomblé significa tanto não estar ainda ritualmente preparado quanto também relaciona-se com a questão da reflexão sobre o ser. A justificativa de Rabelo (2014) é que a sabedoria no candomblé revela a maneira que a pessoa deve ser iniciada na religião.

Nos terreiros a feitura é um processo de iniciação (Oliveira, 1995) no qual o sujeito afirma a relação com o Orixá, tornando-se Iyawo da casa até que cumpra a obrigação de sete anos, o Odun Meje. À medida que a pessoa cumpre as obrigações que seguem à feitura (ritos de três, sete, 14 e 21 anos), ela se torna mais relacionada, mais individualizada e tanto ela quanto as entidades acumulam atributos e ganham mais relações e, portanto, destacam-se devido aos seus vínculos. Com o passar das obrigações, a pessoa avança na hierarquia da casa, ganhando mais autonomia e adquirindo maior responsabilidade. Segundo Rabelo (2014), a formação de filho de santo no candomblé é um processo extenso que requer um intenso trabalho por parte dos mais velhos, mas também requer dele um trabalho sobre si, sobre seu corpo, condutas e disposições, para se transformar, gradualmente, em uma pessoa mais autônoma e relacionada.

Aqueles cujos corpos possibilitam a manifestação ou transe dos orixás são chamados rodantes, termo que direciona o movimento na possessão. A possessão tende a se tornar menos constante entre os que já atingiram a ancianidade no terreiro. Os passos que conduzem à posição de senioridade correspondem a intervalos marcados por ritos: trata-se de criar e fortalecer a relação com a divindade, de aprofundar a sabedoria e criar intimidade. Para Rabelo (2005), a possessão dos rodantes no candomblé é o modo pelo qual as divindades africanas se fazem presentes entre as pessoas; trata-se de um fragmento de um rico continente - em aspectos religiosos e culturais - em solo brasileiro. Diz-se que alguém "virou no/de santo" e/ou que está virado: essas expressões evidenciam a omissão das pessoas e o comando tomado pelas divindades.

Desse modo, os processos de iniciação ou de feitura são de suma importância no candomblé, possibilitando uma discussão inequívoca acerca da identidade e da construção da pessoa. Esse processo tem sido fortemente investigado tanto pela literatura do campo da Antropologia (Goldman, 1985, 2012; Rabelo, 2005, 2014) como da Psicologia (Augras, 1983), permitindo importantes diálogos entre essas inteligibilidades. Para além dessa porosidade fundamental nos estudos dos fenômenos religiosos, este estudo parte de uma investigação ampla sustentada na literatura psicológica, envolvendo a compreensão dos processos identitários tanto de médiuns que realizaram a obrigação de um ano (Camargo, Scorsolini-Comin e Santos, 2018) como a de sete anos (Scorsolini-Comin et al., 2020). Para que tais processos possam ser melhor endereçados no presente estudo, apresenta-se, a seguir, de que modo o candomblé vem sendo contemporaneamente abordado na literatura científica.

\section{Candomblé: ancestralidade e resistência}

O candomblé diz respeito a uma cultura religiosa historicamente muito estudada no Brasil. No entanto, boa parte da produção a respeito de tal cultura é perpassada por intenções e perspectivas racistas e hegemônicas que acabam por singularizá-la e até mesmo alçá-la a um status folclórico, primitivo. 
Vê-se esse movimento por meio das referências clássicas sobre o assunto e amplamente mencionadas nos estudos do candomblé, como Nina Rodrigues ${ }^{1}$ e Arthur Ramos, nomes sabidamente associados à eugenia, e pela falta de obras acadêmicas elaboradas pelo povo do santo ${ }^{2}$ ou a partir da perspectiva de seus protagonistas e suas comunidades. Assim, destaca-se que o conhecimento científico produzido e veiculado sobre o candomblé no Brasil partiu, sobretudo, de uma literatura produzida externamente e não de modo endoperspectivado.

Essa característica atravessa o modo como o candomblé é representado nos meios acadêmicos e como essas imagens também são compartilhadas na produção científica internacional. Assim, destaca-se que o presente estudo se posiciona de modo crítico com relação a essa literatura considerada clássica na área, buscando inteligibilidades nativas que ultrapassem posicionamentos externos e, muitas vezes, de cunho racista. Nesse sentido, a produção de conhecimentos sobre o candomblé veiculada neste estudo partirá das narrativas de seus adeptos, ou seja, do povo de santo.

Os terreiros de candomblé foram construídos à luz de diversas das matrizes africanas que chegaram ao Brasil, dividindo e interpretando-se em nações (Gaia et al., 2020). O presente estudo pesquisou terreiros das nações Ketu e Efon - tendo em vista que essas foram as nações encontradas pelo primeiro autor durante o período de coleta de dados da pesquisa em tela. Sobre essas nações, é oportuno destacar que:

Segundo a bibliografia produzida acerca do candomblé, tanto na nação Ketu, como na nação Efon, o dialeto utilizado é o Yorubá. O Orixá patrono da Nação Ketu desse estudo é Oxóssi, concebido pelos nagôs como a divindade responsável pela caça, sua saudação é Oke Arô (grande caçador) e é concebido como o Orixá que garante o alimento à sua aldeia. Já o terreiro de Nação Efon tem como patronesse a Orixá Oxum, o Orixá maternal, responsável pela água doce, dona do ouro e da beleza. (Scorsolini-Comin et al., p. 6-7)

No entanto, compreende-se que qualquer que seja a nação, o povo de santo acaba sofrendo com a homogeneização (e demonização) de suas culturas religiosas devido ao racismo estrutural (De Deus, 2019) que reverbera no âmbito religioso (Gaia et al., 2020). Dessa forma, é preciso, sempre, pautar-se sobre o palpável, descartando perspectivas do imaginário social e sociológico, na intenção de confeccionar um trabalho científico o mais distante possível de preconceitos que se pretendem dogmas sociais. Outro vértice importante é o poder de fala, de modo que a voz de cada adepto é importante e, tal como seus corpos e crenças, tem sido marginalizada nas análises acadêmicas. A partir desses argumentos, apresenta-se de que modo a mediunidade pode ser pensada nesse contexto.

\section{Por uma compreensão crítica acerca da mediunidade no candomblé}

\footnotetext{
${ }^{1}$ Independentemente de sua obra ser fruto de seu contexto político histórico e social, o teor racista de suas produções acadêmicas é inquestionável e não deve ser ignorado. Cabe ressaltar também que, no primeiro caso, apesar de sua relação com o Candomblé, Nina Rodrigues (1862-1906) escrevia como eugenista, médico e antropólogo.

${ }^{2}$ Nomenclatura popularmente utilizada para denominação dos adeptos/praticantes do candomblé, assim como candomblecista, povo de terreiro e/ou povo do axé.
} 
A mediunidade, por tanto tempo tida como exótica, na medida em que se trata de uma cultura não-branca, também não deixa de ser um aspecto íntimo para cada pessoa. Ela foi ainda um dos principais objetos de estudo dos psicólogos durante o final do século XIX (Shamdasani, 1994), sobretudo aqueles alinhados a perspectivas cognitivistas e da neurociência. Parte dos pesquisadores da época mantinha, diante dos episódios mediúnicos, uma aproximação equivocada, por vezes excessivamente crítica e, em outras vezes, de extrema aceitação; a maioria, porém, enxergava nas práticas mediúnicas apenas uma fraude, um indício ou manifestação de doença mental ou até mesmo uma perigosa ameaça à sociedade. Em que pese o histórico de uma mediunidade por vezes reduzida a possíveis associações com estados psicopatológicos, o que na contemporaneidade tem sido fortemente combatido (Moreira-Almeida, 2013; Paraná et al., 2019; Scorsolini-Comin, 2019; Shamdasani, 1994), Zingrone (1994) assinala que tais aproximações se devem, entre outros, a embates em torno da raça, do gênero e também de cunho religioso, social e político.

Embora a mediunidade possa ser investigada de modo associado a uma religião ou não, destaca-se o candomblé como um contexto importante na discussão do fenômeno em tela, embora a literatura científica produzida por pesquisadores brasileiros tenha priorizado, de certo modo, as expressões mediúnicas ligadas ao espiritismo kardecista, como explicitado anteriormente, sobretudo no contexto da cidade de Uberaba. Os estudos sobre o candomblé, no entanto, priorizaram outras matrizes, como os orixás, as tradições de iniciação e até mesmo as sociabilidades nos terreiros e entre os povos de santo (Camargo et al., 2018; Goldman, 2012; Rabelo, 2014). Mas como podemos compreender a mediunidade no candomblé?

Nina Rodrigues, em seu estudo mais conhecido, $O$ animismo fetichista dos negros baianos (1935), analisou o advento da mediunidade - embora o autor conceba tal dinâmica como "estado de possessão":

Como na possessão demoníaca, como na manifestação espírita, o santo fetichista pode apoderar-se, sob invocação especial do pai-de-terreiro, ou ainda de qualquer filho-de-santo, e por intermédio deles falar e predizer. A pessoa em quem o santo se manifesta, que está ou cai de santo na gíria do candomblé, não tem mais consciência de seus atos, não sabe o que diz, nem o que faz, porque quem fala e obra é o santo que dele se apoderou. Por esse motivo, desde que o santo se manifesta, o indivíduo que dele é portador perde a sua personalidade terrestre e humana para adquirir, com todas as honras a que tem direito, a do deus que nele se revela. (1935, p. 99-100, grifos do autor)

Face ao exposto, é notório o caráter racista da obra do autor, também permeado pelo contexto social do período em que realizou seus estudos. Por isso, para os adeptos de candomblé essas literaturas reforçam, para além do racismo científico, o olhar do branco sobre o negro, inferiorizando-o, sobretudo sua cultura (Nascimento, 2016). Também é oportuno destacar que Nina Rodrigues (1935) concebe o candomblé sob um viés eurocentrado que desconsidera as peculiaridades desta religião. Assim, termos como 'possessão demoníaca' e 'santo fetichista' são utilizados pelo autor.

Em $O$ genocídio do negro brasileiro: processo de um racismo mascarado, ${ }^{3}$ Abdias do Nascimento (2016) ressalta o constante genocídio contra os negros no contexto brasileiro, sobretudo no que se refere à tentativa de apagamento histórico e folclorização de suas

\footnotetext{
${ }^{3}$ Original publicado em 1978.
} 
culturas, bem como ao racismo no campo do simbólico que tende a inferiorizar determinadas religiões "por serem de negros". A partir desse posicionamento crítico, passamos a problematizar o modo como a categoria mediunidade pode ser investigada no contexto do candomblé a partir desses vértices que asseveram a necessidade de adoção de uma perspectiva que possa pensar a construção identitária do ponto de vista de seus próprios personagens.

No caso do candomblé das nações Ketu e Efon, ao ser iniciado, o sujeito passa a ser chamado de Iyawo e pode manifestar o transe de sua divindade, seu Orixá, podendo ainda ser apontado como Ogan (quando homem) ou Èkèjí (quando mulher) (Scorsolini-Comin et al., 2020). Nesses casos, os mesmos não são iniciados, são confirmados, e não têm a capacidade de transe em suas divindades. É preciso mencionar que o processo que antecede a iniciação é o jogo de búzios Ėrìndílógún, pois, ainda que o futuro iniciado já tenha consultado tal oráculo anteriormente, é preciso recorrer a ele para confirmar seu Orixá (Salles, 2010) e saber o que essa divindade gostaria de receber para que seja realizado o ritual de iniciação. O mesmo acontece para consultar Ya Ori e Baba Ajala - Orixás responsáveis pelo ritual do Ebori/Bori, onde a Ori (cabeça) do postulante é fortalecida para poder receber o transe de sua divindade - bem como saber dos ebós (rituais de limpeza e purificação) necessários para determinado procedimento iniciático (Gorski, 2012). O jogo de búzios deve ser consultado nos processos iniciáticos, bem como o obi e o orogbo, pois é através desses sistemas consultivos que os Orixás se comunicarão com o Babalorixá ou a Yalorixá.

Uma das maiores distinções entre Iyawo, Èkèjí e Ogan, mencionados anteriormente, é que Iyawo é aquele que, quando cumpre a obrigação de sete anos, torna-se um Egbon, título que permite que o médium tenha o seu próprio terreiro, se assim tiver caminho ${ }^{4}$, assuma cargos no terreiro e, se preciso, possa conduzir uma cerimônia de Candomblé (ScorsoliniComin et al., 2020). Além do processo de iniciação, esses médiuns devem passar por rituais chamados de obrigação quando completam um, três e sete anos após iniciados. Passado esse período, as renovações ocorrem apenas de sete em sete anos (Verger, ([1981] 2002), as obrigações que comemoram os 14 e 21 anos de iniciação. Já o Ogan é o responsável pela segurança dos terreiros, uma espécie de patrono, também chamado de pai (Nascimento, 2016) $)^{5}$ e a Èkèjí é responsável pela organização das roupas litúrgicas, de vestir os Orixás manifestados nos corpos de seus iniciados e de conduzi-los durante as cerimônias, sendo, por isso, chamada de mãe.

A cultura candomblecista acredita que Èkèjí e Ogan já nascem iniciados e devem ser apontados, suspensos e, por último, confirmados. Vale ressaltar que tal prática difere do rito de iniciação de um Yawo. Alguns adeptos de Candomblé defendem que o termo Ėkèjí seja de origem Fongbe -Jeje, enquanto outros defendem que se trata de Yorubá-Ketu. No entanto, a ausência de literaturas que apresentem a etimologia do termo e igualmente sua conceituação é um fato notório e que dificulta uma conclusão acerca da temática. A partir desse panorama, o objetivo do presente estudo foi compreender os sentidos sobre a mediunidade em médiuns do candomblé iniciados há mais de sete anos.

Trilhando o caminho de diversas investigações que buscam descrever e compreender os movimentos de constituição do candomblé em cidades da Bahia, São Paulo, Rio de Janeiro e Rio Grande do Sul (Bastide, 2009; Prandi, 1990; Verger, 2002), o presente estudo justifica-

\footnotetext{
${ }^{4}$ O que, por sua vez, é definido pelo jogo de búzios/Ėrìndílógún (Salles, 2010).

${ }^{5}$ Importante lembrar que os Ogans surgem como um mecanismo de defesa a perseguição policial (Nascimento, 2016).
} 
se como forma de abordar um assunto ainda pouco explorado: a mediunidade a partir do ponto de vista do médium. Aqui buscou-se abordar tal temática não em uma perspectiva das neurociências (Moreira-Almeida, 2013), mas sim psicossocial e desenvolvimental, de modo a compreender como esse fenômeno se apresenta socialmente e repercute na identidade desses adeptos/praticantes (Camargo et al., 2018; Scorsolini-Comin et al., 2020).

\section{Percursos de uma investigação sobre a mediunidade no candomblé brasileiro}

O presente estudo é fruto de uma pesquisa de caráter qualitativo aprovada pelo Comitê de Ética em Pesquisa da Escola de Enfermagem de Ribeirão Preto da Universidade de São Paulo. Para participar do estudo era necessário ter passado pela obrigação dos sete anos, ser maior de idade e frequentar algum terreiro de modo regular. A escolha da obrigação de sete anos deveu-se ao fato de esses médiuns possivelmente demonstrarem maior engajamento na religião, bem como conhecimentos mais apurados acerca de suas tradições (Goldman, 2012).

Participaram desta investigação 17 adeptos vinculados a três terreiros da cidade de Uberaba-MG, de duas nações distintas: Ketu e Lokiti Efon (que neste estudo será referida simplesmente como Efon). Os participantes estavam inseridos na religião há mais de sete anos e desenvolviam atividades mediúnicas regulares, com frequência mínima de uma vez ao mês. A média de idade dos participantes foi de 32 anos, variando de 21 a 63 anos. A média de idade de santo foi de 19,5 anos, variando entre sete e 52 anos. Os participantes exerciam diferentes funções dentro de suas casas de axé. Foram entrevistados nove homens e oito mulheres. O nível de escolaridade variou desde ensino básico completo até a pós-graduação.

Acerca do contexto de produção deste estudo, recupera-se o modo como a religiosidade é uma categoria fundante na sociedade de Uberaba. Com uma forte tradição católica, a cidade passou a ser reconhecida como capital do espiritismo kardecista no Brasil a partir da presença do médium Chico Xavier, que viveu no município por muitos anos, desenvolvendo grande parte da sua atuação neste período, que coincidiu com a popularização do espiritismo no Brasil (Jabert, 2011). Para além dessas manifestações, observa-se no município grande presença de terreiros de umbanda e de candomblé, conforme apontado em estudos anteriores (Camargo et al., 2018; Scorsolini-Comin et al., 2020).

Os dados foram coletados por meio da técnica da História Oral de Vida (Hernández, 2010). Com essa técnica busca-se compreender de que maneira a pessoa constrói explicações e descrições para sua própria trajetória, elencando momentos, eventos, situações e relacionamentos que ela considere relevantes para a construção da sua identidade. Em seguida, foi aplicada uma entrevista semiestruturada, a fim de cotejar perguntas específicas sobre a mediunidade e a experiência da iniciação.

Em cada terreiro, os primeiros entrevistados foram os dirigentes do local. Isso permitiu obter o consentimento para as demais entrevistas e propiciou conhecimentos normativos e estruturais de cada terreiro. Os responsáveis pelos terreiros indicaram alguns participantes, sendo eles os mais experientes (definida de acordo com a idade de iniciação no candomblé). Após as devidas apresentações, leitura e assinatura do Termo de Consentimento Livre e Esclarecido, as entrevistas foram aplicadas individualmente.

As entrevistas audiogravadas, bem como as histórias de vida, foram transcritas na íntegra para posterior análise. De acordo com o que recomendam Braun e Clarke (2006), o corpus do estudo foi organizado a partir dos procedimentos de familiarização dos dados, da 
geração de códigos iniciais, da busca de temas que apareceram nos agrupamentos de dados, da revisão dos temas, da definição e nomeação dos temas e da produção de um relatório. Os temas emergentes na análise do corpus foram organizados em três sentidos principais, discutidos a seguir: os sentidos sobre a mediunidade, os sentidos sobre a corporeidade no transe de possessão e, por fim, os sentidos individuais sobre a experiência de ser médium. A interpretação dos dados obtidos foi pautada na literatura acerca da mediunidade e do candomblé, também dialogando com o referencial bioecológico de Bronfenbrenner (2011) para a compreensão dos processos desenvolvimentais.

\section{O candomblé e a construção da pessoa}

Foi possível identificar a relação estabelecida pelos médiuns com a religião, a mediunidade, as entidades e com os irmãos e pais de santo. Essas relações são estabelecidas pela reciprocidade, cumplicidade, respeito e carinho, auxiliando e ajudando no desenvolvimento e aprendizado do próximo. Os relacionamentos e interações realizados pelos médiuns nos terreiros envolvem tanto a relação com os irmãos e pais de santo e familiares, que se encontram no mundo terreno, como também com entidades que fazem parte do mundo espiritual. Há uma forte ligação entre o filho de santo e seu Orixá, considerado na religião como o "dono de sua cabeça". A partir das obrigações devotadas ao Orixá e com o decorrer dos anos, essa relação se fortifica, aumentando, então, a responsabilidade e o compromisso do médium para com o seu Orixá. Da mesma forma, o filho de santo cria maior sabedoria para poder passar esse conhecimento adiante para os seus filhos de santo. Assim, percebe-se um desenvolvimento tanto do médium em relação ao seu mundo espiritual, representado pelo seu Orixá, como em relação à sua comunidade de referência, representada nos relacionamentos interpessoais estabelecidos no terreiro.

O convívio e relação com a religião e a fortificação do relacionamento do médium com os seus orixás possui como uma possível consequência a mudança de como ele se relaciona consigo mesmo e com os outros dentro e fora da religião. Através de um trecho obtido de uma das entrevistas realizadas é possível identificar essa mudança na relação com os outros:

Eu continuo uma pessoa, um ser humano como qualquer outro que sofre todas as demandas de qualquer outra, com um diferencial: eu tenho uma fé aclarada, aflorada em mim, né? (...) Eu tenho consciência de que o que eu carrego é uma ancestralidade que fala através do meu búzio; ele não fala através do meu olhar, eu não tenho dom de ver nada, tá? [...] Algumas coisas, claro que você percebe depois com tempo (...), mas é a experiência de vida e não é espiritualidade falando, tá? (Participante 10)

Esse relato mostra a mudança que o entrevistado obteve como pessoa e no modo como ele passa a se relacionar com os outros. Um importante marcador dessa fala é o destaque ao fato de que a espiritualidade não significa a vidência, necessariamente, ou a capacidade de se tornar uma pessoa melhor, mas justamente a de tornar-se alguém que possui maior consciência de si e da sua espiritualidade. Embora essa consciência mais ampliada possa promover mais amadurecimento, isso não significa qualquer superioridade em relação às pessoas que não passaram pelo mesmo processo de desenvolvimento espiritual. Assim, as mudanças narradas pelo Participante 10 referem-se a uma perspectiva individual que se 
mostra consciente de que existem processos relacionados à espiritualidade e outros que se dão independentemente desse universo da fé, que é a própria dimensão do sujeito. Porém, quando questionado a mais médiuns sobre a possível mudança em seu modo de relacionar com os outros, houve entrevistados que negaram a mudança, como se percebe no seguinte fragmento:

Não, eu acho que nós estamos constantemente mudando a forma de lidar com as pessoas, eu lido com as pessoas (...) não é em razão da religião ou pela ausência, eu acho que a falta de religião dificulta os relacionamentos, porque eu acho que onde Deus está... ou qualquer sagrado (...), onde existe uma pessoa que tem fé no sagrado, é uma pessoa que tem amor pra dar, que tem um bom conselho, que tem sempre um abraço pra te transmitir alguma coisa de positivo. (Participante 1)

A participante 1, desse modo, sublinha a sua experiência religiosa como algo que a torna mais madura e consciente, vivência essa que outras pessoas poderiam acessar se também desenvolvessem a sua espiritualidade. Assim, o seu pertencimento religioso e a sua iniciação como médium são fatores que contribuíram para as mudanças positivas em sua vida com o passar do tempo.

Há que se problematizar, no entanto, que os médiuns entrevistados não narram os possíveis conflitos identitários que normalmente são esperados ao longo tanto do processo de reconhecimento da mediunidade (Scorsolini-Comin e Campos, 2017) quanto de iniciação (Camargo et al., 2018). Assim, não permitem o acesso ao jogo das identidades (Hall, 2006) que caracteriza a construção da pessoa. Esse processo talvez possa se dar em função de serem médiuns considerados experientes, que já realizaram a feitura dos sete anos e representarem um importante papel em suas comunidades e na preservação dos saberes do candomblé. Ainda assim, as transições ecológicas narradas, envolvendo as mudanças de papel e de ambiente (Bronfenbrenner, 2011), podem ser indícios importantes desse processo, como destacado nos percursos aqui enlevados.

\section{Mediunidade para os iniciados no candomblé}

Ao serem questionados sobre o que pensam sobre o que é a mediunidade, houve respostas diversificadas. As explicações sobre a mediunidade envolveram desde a associação da ligação do mundo terreno com o sagrado, da sensação que o médium sente no processo de incorporação até sobre a interpretação sobre a mediunidade ser um dom ou sobre ela ser algo que todos possuem. É possível observar as variadas respostas nos seguintes trechos:

Mediunidade é uma faculdade que acredito que todas as pessoas têm, algumas desenvolvidas outras não desenvolvidas, que é... permite a você uma evolução, permite a você um contato com o mundo espiritual, permite a você uma, ser um elo de ligação entre o sagrado e o mundo em que vivemos. (Participante 1).

É uma forma de plasma, quando você entra do estado sólido, o plasma é uma forma assim, é o que eu acho que... que é... parece que a gente, parece que o corpo da gente amolece totalmente né, a carne que é.... é nervo, osso, parece que elas descolam de tudo e vira um plasma (...) (Participante 8) 
Mediunidade você não adquire por livre e espontânea vontade, a gente fala que.... a gente nasce com a mediunidade, mediunidade é um dom, para mim é um dom. (Participante 3)

Eu acho que mediunidade é antes da questão do incorporado deixar de incorporar. Porque muita gente tem mediunidade e não incorpora, né? Existem várias etapas, várias fases da mediunidade. Mas a mediunidade é isso aqui que nos contorna, entendeu? Esse espaço que está para além de mim é mediunidade. Eu não tenho muito como explicar mediunidade, para mim mediunidade é uma fase de transe porque eu incorporo o que eu não consigo explicar, sabe? Não tem um meio, um começo, meio e fim. Tem um espaço que não há explicação para o que acontece, né? Que é um torpor, que é uma tontura, que é escurecer de olhos (...). É um outro ser, é uma outra energia que está em você falando pela sua boca, ouvindo pelo seu ouvido, vendo pelos seus olhos, cheirando e sentindo pelo seu corpo e não é você né? Como explicar isso tudo? Muito complexo e ao mesmo tempo dá um medo danado porque não é você. Ao mesmo tempo dá uma alegria danada porque você sabe que não é você, mas sabe que está acontecendo. E aí? É muito louco, dá uma tese, viu? (Participante 10)

As explicações trazidas pelos médiuns revelam diferentes sentidos sobre essa mediunidade. Emergem, por exemplo, tentativas de explicar quase que cientificamente a manifestação do transe de possessão, em uma possível necessidade de validar ou de reconhecer a veracidade dessa experiência. Essa tentativa também pode ser interpretada como a necessidade de explicar a um pesquisador que, pretensamente, não passaria por essa experiência, como ela poderia ser manifestada em seu corpo. Assim, a descrição pormenorizada da mediunidade seria uma possibilidade de trazer mais para perto das pessoas que não possuem essa faculdade as sensações relacionadas ao transe, por exemplo. As menções a linguagens mais rebuscadas ou mesmo ao domínio científico podem sim ser um viés de desejabilidade social pelo fato de essas entrevistas terem se dado no contexto de um estudo científico. Mas, para além disso, esses médiuns parecem demandar a necessidade de serem reconhecidos nessas experiências, ou seja, de provar que, de fato, tais manifestações existem, podem ser vistas e investigadas mais detidamente.

Também emerge o sentido do controle consciente acerca da experiência de mediunidade, ou seja, de que apesar de todos possuírem algum nível de mediunidade, ela só poder ser manifestada a partir do desejo ou do assentimento do médium. Outros relatos, ao contrário, revelam que se trata de uma faculdade que não se poderia recusar, no domínio de um dom que se possui e que deve ser corporificado independentemente da vontade da pessoa. Desse modo, dois movimentos distintos aparecem na perspectiva dos médiuns: a mediunidade como algo que se crava no destino do médium e que deve ser experienciado independentemente da sua vontade e, em uma segunda acepção, como uma capacidade que, para ser expressa, deve ser permitida, consentida, cujo controle consciente é manifestado pelo médium. Na primeira acepção, percebemos uma mediunidade que não pode ser controlada pelo médium. Na segunda, é o médium quem teria a função de controlar a manifestação dessa mediunidade, podendo inclusive recusar-se a essas expressões.

Outro sentido bastante presente não apenas nesses participantes, mas em estudos realizados com outros médiuns, no caso, da umbanda (Scorsolini-Comin e Campos, 2017) é o da mediunidade como uma faculdade presente em todas as pessoas no contexto candomblecista, haja vista que o que entendemos por mediunidade no presente estudo não é, necessariamente, a manifestação religiosa ou a capacidade de manifestação religiosa que determinado adepto possui, mas as dinâmicas mediúnicas, ou seja, ao jogar um obi para confirmação de determinada obrigação, ao tocar os atabaques em determinada cerimônia 
religiosa e/ou ao entoar cânticos aos orixás, os sujeitos exercem sua mediunidade, pois esse fenômeno - da mediunidade - não pode ser compreendido, nessa religião, à luz das religiões europeias ou cristãs, pois possui suas próprias dinâmicas ao sul.

Nesse sentido da mediunidade como algo presente em todas as pessoas no candomblé, nota-se uma perspectiva de democratização da mediunidade e do conhecimento hierárquico religioso, ou seja, a mediunidade não seria apenas algo para os escolhidos, os iniciados, mas atravessariam o humano, sendo que o seu acesso poderia ser oportunizado, dimensionado e costurado a partir do pertencimento religioso (Araújo, 2012, 2018). Assim, pertencer ao candomblé, ser iniciado no candomblé (Goldman, 2012; Rabelo, 2014) seria uma oportunidade de assumir e experienciar, de fato, a mediunidade. As pessoas que não tiverem esse mesmo pertencimento terão possivelmente trajetórias distintas, podendo desenvolver-se mediunicamente em outras religiões ou até mesmo não assumindo ou reconhecendo esses fenômenos se estiverem engajadas em religiões que não abram espaço para essa manifestação ou mesmo se não tiverem qualquer pertencimento religioso.

Podemos concluir, pelos sentidos disponíveis nas entrevistas com esses médiuns, dois sentidos principais sobre a mediunidade, que transita ora como faculdade que é interpretada como um dom, diferenciando o médium das demais pessoas, ora como característica comum a todas as pessoas, sendo que a diferença estaria no fato de essa pessoa possuir consciência dessa faculdade ou mesmo estar ou não engajada em alguma religião. Pertencer ao candomblé, como nas narrativas dos participantes, é a possibilidade de legitimar essa expressão e interpretá-la dentro de uma mística específica, dentro de um ethos que a naturaliza e a sacraliza.

Por fim, recorrendo à literatura de Mauss (1974), também o sentido de dom pode ser problematizado, o que se materializa, nestes excertos, na obrigatoriedade da troca e da retribuição, ou seja, de que esse dom representado pela mediunidade seria dado ao médium para que ele pudesse empregá-lo com uma finalidade, notadamente de prestação de algum serviço ou benefício ao próximo e à sociedade. Assim, esse dom teria um sentido que não se centralizaria nas características do médium, necessariamente, mas dentro da lógica da dádiva, o que envolveria noções como as de honra e prestígio, fortemente valorizadas no candomblé e que ultrapassariam a dimensão da pessoa, dialogando diretamente com as sociabilidades e a sustentação dessas relações ao longo do tempo.

\section{A mediunidade narrada no corpo}

Quando questionados sobre as sensações corpóreas que possuem ao incorporarem, haja vista que todos os iniciados são médiuns de incorporação - ou rodantes, na terminologia do candomblé, foi relatada uma variedade de sensações: coração acelerado, peso, emoção, energia forte, sensação quente do corpo, como também sensação de anestesia e adormecimento. Essas sensações são descritas nos seguintes recortes:

Quando é Iansã é meio mesmo que um vento... quando ela vai embora eu fico quente, parecia, parece que eu saí de um dentro de um caldeirão fervendo, fico quente mesmo, muito quente, quando ela vai embora ela me deixa muito quente.... quando é Brasinha por exemplo, eu começo a me sentir meio agitada, mais feliz, aquela coisa de criança... aquela coisa de criança... gostosa, sabe... quando é caboclo eu não sei falar do caboclo não, também o caboclo me pega como se fosse um vento, a maioria das entidades como um espetão, sabe... não sei.

Revista Cultura \& Religión Vol. XIV, 2020 № 2 (julio-diciembre) 
Eu não sinto aqueles tremores, aquelas coisas não, já me pega.... a pombagira me pega como vento, depois ela me deixa muito tempo fora de mim, eu fico uma meia hora ainda pra voltar, mas a energia da minha pomba gira é muito forte, é muito viva, sabe, então eu acho que é por isso, pra você ver da última festa eu fiquei desmaiada, deitei e dormi... o preto velho me deixa leve, caboclo me deixa leve depois vai embora, marujo, baiano, só iansã que me deixa muito quente... e a pomba gira me tira a energia. (Participante 2)

Olha, a energia que passa... cada um sente de um jeito, mas ela é uma coisa que, tipo, dependendo do Orixá a gente sente o coração disparar, sente o vento passar, é o que eu digo, são coisas que só quem sente sabe, entendeu, mas é uma energia, essa energia, então cada um é de um jeito. (Participante 4)

É tipo anestesia, parece que você tá sendo anestesiado e aquilo vai tomar parte do seu corpo até.... você ficar anestésico geral, é assim que eu sinto. (Participante 8)

A partir desses relatos, alguns sentidos podem ser discutidos. $\mathrm{O}$ primeiro deles é o caráter da manifestação estar diretamente associado ao tipo de entidade/orixá que se incorpora. Assim, a natureza dessa entidade direcionaria o modo como a incorporação ocorreria em termos de início do transe, da possessão em si e até mesmo das sensações após a desincorporação. Nesse ponto destaca-se a relação indissociável entre as características do orixá com as do médium, em um processo de metamorfose (Augras, 1983), de modo que não se poderia interpretar o médium sem acessar essa dimensão do orixá (Godoy e Bairrão, 2014). Não se trata, pois, de sensações individualizadas, segundo cada médium, mas de experiências relacionadas à natureza, ao modo de ser e às qualidades das entidades incorporadas, seus símbolos e características.

As diferenças corpóreas narradas a partir do contato com cada entidade/orixá ficam claras na narrativa da Participante 2, que destaca as diferenças entre as incorporações das entidades por ela corporificadas. Iansã, por exemplo, que possui a mística das tempestades e dos ventos, é sentida como uma energia de passagem, de trânsito, como a rapidez do vento. A incorporação dessa Orixá, portanto, seguiria a sua mesma gramática, sendo que o médium sentiria, em seu corpo, a manifestação dessas características ao receber a energia de Iansã.

Outras sensações narradas falam de um duplo movimento: o de aceleração e, paradoxalmente, o de paralisia. Assim, as experiências corpóreas podem transitar de uma paralisia, de um torpor, até mesmo a uma aceleração e intensa movimentação. Essas sensações também podem estar associadas à qualidade de cada entidade e sua natureza. Não foram trazidas menções às características dos médiuns que possam estar associadas a esses movimentos sentidos/experienciados durante o transe de possessão. Assim, pode-se afirmar que a experiência do transe, para esses médiuns, é construída pelas entidades por eles incorporadas, não havendo características do próprio médium (físicas, por exemplo), que poderiam atravessar o fenômeno da incorporação. O sentido do transe, aqui, parece ser conduzido única e exclusivamente pelas entidades incorporadas, pelas energias dos Orixás.

No entanto, pode-se afirmar que esse processo pode fazer referência às identidades das entidades/orixás, transmitidas oralmente e compartilhadas nos domínios religiosos dessas comunidades, fortalecendo a interpretação de uma identidade que não se manifesta apenas em nível individual, mas que também é fruto de uma coletividade, de uma ancestralidade (Augras, 1983). Para além dessa interpretação calcada no plano coletivo, histórico e ancestral, também uma noção de identidade ligada a aspectos individuais emerge como uma 
possibilidade compreensiva, costurando características pessoais àquelas cultural e religiosamente atribuídas às entidades/orixás (Godoy e Bairrão, 2014; Scorsolini-Comin e Campos, 2017). O sentido do transe, desse modo, não poderia ser compreendido apenas por uma interpretação da dimensão coletiva, mas por meio de experiências identitárias que costuram, a todo momento, o eu e o outro, o mundo interno e o externo, fortalecendo uma noção de pessoa para além das inteligibilidades ocidentais, como discutido a seguir.

\section{Identidade e desenvolvimento em médiuns do candomblé}

O candomblé é uma religião com uma forte vivência comunitária, de modo que nenhum médium pode se desenvolver de modo individual e a despeito do seu contexto e das relações estabelecidas no terreiro de referência. Embora a iniciação seja um processo individual, diferentes personagens participam desse momento, de modo que também podemos conceber esse momento como uma experiência grupal, coletiva. Nesse processo, chama atenção o diálogo com o mundo espiritual. Assim, a mediunidade é um fenômeno que permite o diálogo do médium com o plano sagrado, representado pelas entidades e pelos orixás. Ao dialogar com essas instâncias, sendo ouvido e também podendo ouvir, por meio da mediunidade, tais elementos passam a ter uma concretude na experiência do médium. Desse modo, as entidades não são elementos externos, distanciados do sujeito, mas justamente polos de referência constante, com quem se pode entrar em contato, conversar, sentir, ouvir um conselho. Essa ligação geraria a sensação de uma rede de apoio protetora e orientadora importante na experiência religiosa desses médiuns na iniciação de sete anos.

Se pensarmos nas contribuições de Bronfenbrenner (2011) para o estudo do desenvolvimento humano, pode-se afirmar que os Orixás, para esses médiuns, não representam um contexto desenvolvimental, um lugar onde essas pessoas possam se desenvolver, interagir e aprender, por exemplo, mas sim identidades que estão em diálogo profundo com esses médiuns, em seus microssistemas, estabelecendo relações proximais de confiança, vinculação e identificação (Camargo et al., 2018). Essa interpretação nos permite afirmar que, a despeito de um mesmo Orixá ser corporificado por diferentes médiuns, por exemplo, o modo como cada médium irá se desenvolver a partir do diálogo com o seu Orixá é diferente. Essa individualização nos permite considerar que os elementos que diferenciam essas experiências, portanto, dizem respeito ao médium. Portanto, abre-se a necessidade de compreender os percursos desenvolvimentais desses médiuns e suas histórias individuais, a fim de que se possa analisar a mediunidade como algo que se costura à experiência de cada um, contribuindo para as mudanças desenvolvimentais.

A feitura é considerada pelos médiuns como um renascimento (Goldman, 2012; Rabelo, 2014), e com isso emerge a mudança na identidade do indivíduo, que pode ser entendido como uma modificação no papel desempenhado pela pessoa. Essa mudança de papel - de fiel para médium iniciado - representa uma transição ecológica. Essa transição ecológica tanto é uma evidência de que está havendo o processo de desenvolvimento como um convite para que novos processos desenvolvimentais aconteçam. Assim, a iniciação, aqui, emerge como um elemento que revela o processo desenvolvimental, mas que também atua como promotor de desenvolvimento (Bronfenbrenner, 2011; Camargo et al., 2018).

Esse processo emergiu em médiuns mais experientes (com a feitura de sete anos), mas também foi mencionado em estudo realizado com médiuns que realizaram a primeira 
iniciação, a de um ano (Camargo et al., 2018). Desse modo, não pudemos observar mudanças significativas em relação à mediunidade tendo como variável norteadora o tempo de iniciação. O tempo de iniciação parece ter efeitos mais macrossociais, na medida em que o processo de iniciação de sete anos amplia os conhecimentos do médium e o coloca em uma posição de maior destaque, fazendo também com que passe a ser responsável pelas comunicações com membros mais novos ou menos experientes, e até mesmo a ser um interlocutor com o ambiente fora do terreiro. Nesse sentido, esses médiuns parecem estar mais preparados para a comunicação com a comunidade externa, representando o candomblé, os preceitos ali confirmados e o modo de ser desses filhos de santos.

As mudanças mencionadas também incluem as novas funções adquiridas pelos médiuns através dos anos por meio de suas obrigações. As alterações sofridas pelos médiuns podem ser observadas no modo pelo qual interagem com outras pessoas após o processo de feitura de santo e do fortalecimento de sua relação com os orixás. É possível observar essa mudança no seguinte relato:

Totalmente, eu sou bem mais equilibrada, não, a gente aprende a observar, sabe, o que fala, e a gente se torna exemplo, né, então o que que acontece, eu tenho que dar o bom exemplo, porque hoje em dia, principalmente, mas assim, a vida inteira desde o início eu sempre fui muito cobrada, sabe, então eu sempre tinha que ser exemplo, então... você tem que aprender a controlar as suas emoções (...) (Participante 2)

As mudanças presentes estão relacionadas ao processo de desenvolvimento vivido pelos médiuns no terreiro, fazendo com que elementos do macrossistema, no caso o candomblé, sejam modificados ou adaptados em virtude das necessidades do microssistema, representado pelo terreiro. A permanência no terreiro e a realização das feituras e obrigações proporcionam a mudança na forma pela qual o médium se relaciona com outros microssistemas, como a família, os amigos, o trabalho, entre outros, adensando os elementos que devem ser analisados para acompanhar os processos desenvolvimentais desses médiuns (Bronfenbrenner, 2011; Camargo et al., 2018).

A partir dos sentidos aqui compartilhados, pode-se compreender que a mediunidade é um fenômeno que parece demandar do candomblé um olhar para as individualidades de seus adeptos. Em que pesem os elementos da ancestralidade e das tradições de base coletivista e comunitária que compõem o candomblé, a mediunidade parece funcionar como um elemento que depende fundamentalmente do modo como esse médium vive e vivencia esse fenômeno. Assim, os elementos individuais parecem costurar de modo relevante a forma como esse médium se situa dentro do candomblé, convidando-o para um olhar para os seus processos, os seus interlocutores e até para as próprias sensações e sentimentos evocados durante o transe de possessão e ao longo das feituras realizadas.

Dialogar entre esses dois aspectos, indivíduo e coletividade, parece ser um apontamento legítimo diante dos percursos desenvolvimentais recuperados no presente estudo. Além disso, o jogo produzido por essas identidades (Hall, 2006) pode e deve ser apreendido de modo perene, abrindo espaço para os embates, as descontinuidades e também as permanências que compõem a pessoa e que parecem ser acolhidos pelos participantes do estudo, ainda que predomine uma dimensão bastante linear e, até certo ponto, representativa de uma necessidade de apresentar tanto a mediunidade como o pertencimento ao terreiro apenas com acepções positivas, desconsiderando a dimensão do embate e do conflito que 
permeia a construção do médium, como explorado na literatura (Scorsolini-Comin e Campos, 2017). Aventa-se que esse posicionamento possa se dar não apenas por meio da desejabilidade social, mas pela tentativa de combater o racismo e a intolerância que incidem sobre as religiões de matrizes africanas, sobretudo no contexto brasileiro contemporâneo.

\section{Considerações finais}

Compreende-se, a partir da análise das entrevistas, que as experiências dos médiuns do candomblé iniciados há mais de sete anos, assim como as relações estabelecidas em sua comunidade religiosa e as transformações identitárias e sociais experienciadas por estes médiuns, são vivências que influenciam no desenvolvimento do indivíduo e que geram uma repercussão nas pessoas de seu convívio. Esse processo de desenvolvimento abrange o mundo material e o mundo espiritual, fatores que determinam quais experiências serão vividas pelo indivíduo.

A análise dos dados nos permite reconhecer a busca dos médiuns em reforçar suas singularidades, ressaltando que não estão acima ou abaixo de ninguém pelo seu dom ou capacidade mediúnica. As entrevistas mostram também que o processo de incorporação é muito particular, inseparável do corpo do médium e inexplicável para a maioria deles. Essa dimensão do inexplicável faz referência àquilo que não é do sujeito, mas da entidade/orixá. Esses elementos, desse modo, não poderiam ser controlados pelo médium, mas apenas experienciados, corporificados.

No mais, importa ressaltar que a ascensão de cargos, obrigações e da autonomia do sujeito no terreiro, como também os conhecimentos adquiridos pelo médium, são aspectos importantes que determinam a transição ecológica vivenciada pelos indivíduos da religião. Esses fatores modificam o modo pelo qual o médium observa e enfrenta as diferentes situações do dia-a-dia, pois é a partir do conhecimento e da forte ligação com os Orixás que o indivíduo vai sendo moldado para compreender melhor as situações do cotidiano, tanto dentro quanto fora do terreiro. Portanto, conclui-se que a religião altera o modo que a pessoa lida com os outros microssistemas, ao passo que toda a sua vida é afetada não simplesmente pela mediunidade, mas pela fidelidade ao terreiro, no tocante à identidade e o modo de entender, ser e estar no mundo.

Pode-se concluir que esses médiuns, por gozarem de maior prestígio em suas comunidades e por serem responsáveis pela transmissão de conhecimentos acerca do candomblé dentro e fora dos seus terreiros, encontram-se engajados em compartilhar experiências que evoquem fundamentalmente os aspectos positivos relacionados à mediunidade, incorporando, inclusive, uma gramática científica que visa a explicar o fenômeno. Na tentativa de valorizar o candomblé em um cenário de intolerância e racismo, este parece ser um movimento que valoriza a mediunidade e a coloca em uma posição de destaque dentro das expressões das religiões de matriz africana.

Por fim, dois pontos merecem ser sublinhados. O primeiro refere-se ao fato de que, a despeito de uma interpretação que destaca os aspectos coletivos e comunitários das religiões afro-brasileiras, pudemos compreender, com o presente estudo, que a vivência da mediunidade é bastante individual, de modo que a mediunidade parece ser um elemento, dentro de uma religião mais coletivista, capaz de enlevar os aspectos individuais do sujeito e que se cravam em suas expressões religiosas, em seus trânsitos e no modo como vivencia 
esse pertencimento. Outro aspecto a ser posto em evidência diz respeito ao estudo da mediunidade como um convite para que esses médiuns possam apreciar os percursos individuais dentro da religião. Ao assumirem uma perspectiva essencialmente individual acerca da mediunidade, pode-se destacar que esse aspecto se torna até mais relevante do que cada religião legitima ou não em termos dessa mediunidade. $\mathrm{O}$ que os dados aqui nos permitiram compreender, portanto, é que por mais que a religião possua uma gramática específica acerca da mediunidade, é a experiência do médium que a torna, de fato, algo concreto não apenas como ritual ou manifestação do sagrado, mas como experiência identitária que atravessa e constitui esses médiuns em seus ciclos vitais.

\section{Referências Bibliográficas}

Araújo, P. C. (2012). Awo Òrìsà: o segredo ritual como fonte de poder dos ègbónmi. Revista Nures, $\operatorname{VIII}(22), 1-23$.

Araújo, P. C. (2018). Segredos do poder: hierarquia e autoridade no Candomblé. São Paulo: Arché.

Augras, M. (1983). O duplo e a metamorfose: a identidade mítica em comunidades nagô. Petrópolis, RJ: Vozes.

Augras, M. (2012). A segunda-feira é das almas. Rio de Janeiro: Pallas.

Bastide, R. (2009). O candomblé da Bahia. Rio de Janeiro: Companhia das Letras.

Braun, V. e Clarke, V. (2006). Using thematic analysis in psychology. Qualitative Research in Psychology, 3(2), 77-101.

Bronfenbrenner, U. (2011). Bioecologia do desenvolvimento humano: tornando os seres humanos mais humanos. Porto Alegre: Artmed.

Camargo, A. F. G., Scorsolini-Comin, F. e Santos, M. A. (2018). A feitura do santo: percursos desenvolvimentais de médiuns em iniciação no candomblé. Psicologia \& Sociedade, 30, e189741.

Carvalho, E. F. e Fernández, F. R. (2017). La libertad religiosa en Brasil y su regulación en la Constitución. Cultura y Religión, 11(1), 110-128.

De Deus, L. O. (2019). Por uma perspectiva afrorreligiosa: estratégias de enfrentamento ao racismo religioso. Rio de Janeiro: Fundação Heinrich Böll.

Gaia, R. S. P., Vitória, A. S. e Roque, A. (2020). Candomblé no Brasil: resistência negra na diáspora africana. Jundiaí: Paco Editorial.

Godoy, D. B. O. A., e Bairrão, J. F. M. H. (2014). A psicanálise aplicada à pesquisa social: a estrutura moebiana da alteridade na possessão. Psicologia Clínica, 26(1), 47-68.

Goldman, M. (1985). A construção ritual da pessoa: possessão no candomblé. Religião $e$ Sociedade, 12(1), 22-54.

Goldman, M. (2012). O dom e a iniciação revisitados: o dado e o feito em religiões de matriz africana no brasil. Mana, 18(2), 269-288.

Gorski, C. (2012). Ritual de iniciação no Candomblé de Ketu: uma experiência antropológica. Revista Todavia, 3(4), 52-64.

Hall, S. (2006). A identidade cultural na pós-modernidade. Rio de Janeiro: DP\&A.

Hernández, G. (2010). Conversiones religiosas e historia oral: pentecostales y mormones en contextos migratorios, en Bahía Blanca y área de influencia. Cultura y Religión, 5(1), 135-155. 
Jabert, A. (2011). Estratégias populares de identificação e tratamento da loucura na primeira metade do século XX: uma análise dos prontuários médicos do Sanatório Espírita de Uberaba. História, Ciências, Saúde-Manguinhos, 18(1), 105-120.

Kardec, A. (2003). Livro dos médiuns. 71ª ed. Rio de Janeiro: Federação Espírita Brasileira.

Ludueña, G. (2013). Estudios sociales contemporáneos sobre el espiritismo argentino: ciencia, religión e institucionalización del espíritu. Cultura y Religión, 6(1), 42-59.

Mauss, M. (1974). Ensaio sobre a dádiva. Forma e razão da troca nas sociedades arcaicas. Sociologia e Antropologia. Vol. II. São Paulo: EDUSP.

Montero, P. (2013). Religião, laicidade e secularismo: um debate contemporâneo à luz do caso brasileiro. Cultura y Religión, 7(2), 13-31.

Moreira-Almeida, A. (2013). Pesquisa em mediunidade e relação mente-cérebro: revisão das evidências. Revista de Psiquiatria Clínica, 40(6), 233-240.

Nascimento, A. (2016). O genocídio do negro brasileiro: processo de um racismo mascarado. $3^{\mathrm{a}}$ ed. São Paulo: Perspectiva.

Nina Rodrigues, R. (1935). O animismo fetichista dos negros baianos. Rio de Janeiro: Civilização Brasileira.

Oliveira, J. R. (2016). Territorialidades de la fe en el catolicismo brasileño: espacialidad y temporalidad en las nuevas comunicaciones. Cultura y Religión, 10(2), 65-79.

Paraná, D., Rocha, A. C., Freire, E. S., Lotufo Neto, F. e Moreira-Almeida, A. (2019). An empirical investigation of alleged mediumistic writing: a case study of Chico Xavier's letters. Journal of Nervous Mental Disease, 207(6), 497-504.

Prandi, R. (1990). Modernidade com feitiçaria: candomblé e Umbanda no Brasil do século XX. Tempo Social, 2(1), 49-74.

Rabelo, M. C. M. (2005). Rodando com o santo e queimando no espírito: possessão e a dinâmica de lugar no candomblé e pentecostalismo. Ciências Sociais e Religião, 7(7), 11-37.

Rabelo, M. C. M. (2014). Enredos, feituras e modos de cuidado: dimensões da vida e da convivência no candomblé. Salvador: EDUFBA.

Oliveira, A. B. (1995). Elégùn: iniciação no Candomblé feitura de İyàwó Ogán e Ekéjì. Rio de Janeiro: Pallas.

Salles, N. R. (2010). Búzios: a fala dos Orixás. 2a ed. Rio de Janeiro: Pallas.

Scorsolini-Comin, F. (2019). Mediumship and mental health: tensions from ethnopsychiatry/ethnopsychology. International Journal of Development Research, 9(9), 29957-29962.

Scorsolini-Comin, F. e Campos, M. T. A. (2017). Narrativas desenvolvimentais de médiuns da umbanda à luz do modelo bioecológico. Estudos e Pesquisas em Psicologia, 17(1), 364-385.

Scorsolini-Comin, F., Ribeiro, A. C. S. e Gaia, R. S. P. (2020). Tradição e socialização nos terreiros de candomblé de Uberaba-MG: análise bioecológica dos percursos religiosos. Psicologia \& Sociedade, 32, e223042.

Shamdasani, S. (1994). Encountering Hélène: Théodore Flournoy and the genesis of subliminal psychology. In T. Flournoy, From India to the Planet Mars: a case of multiple personality with imaginary languages (pp. xi-li). Princeton, NJ: Princeton University Press.

Silva, V. G. (Org.) (2015). Intolerância religiosa: impactos do neopentecostalismo no campo religioso afro-brasileiro. São Paulo: EDUSP. 
Verger, P. F. ([1981] 2002). Deuses iorubás na África e no Novo Mundo. (M. A. Nóbrega, Trad.). Salvador: Corrupio.

Zangari, W. (2003). Incorporando papéis: Uma leitura psicossocial do fenômeno da mediunidade de incorporação em médiuns de umbanda. (Tese de doutorado), Instituto de Psicologia, Universidade de São Paulo, São Paulo, SP.

Zingrone, N. L. (1994). Images of woman as medium: Power, pathology and passivity in the writings of Frederic Marvin and Cesare Lombroso. In L. Coly \& R. A. White (eds.), Women and Parapsychology: Proceedings of An International Conference (pp. 90-123). New York: Parapsychology Foundation.

\section{Cómo citar este artículo}

Scorsolni-Comin, F.; Vilela de Godoy, H y Da Silva, R. (2020). Sentidos da mediunidade nos candomblés Ketu e Efon. Revista Cultura \& Religión, 14(2), 35-55. 